\title{
ANALISIS SEMIOTIKA DAN PESAN SOSIAL PADA IKLAN COCA-COLA VERSI AVATAR
}

\author{
Nichi Hana Karlina \\ Fakultas Komunikasi dan Desain, Universitas Informatika dan Bisnis Indonesia \\ email: nichi.hana@yahoo.com
}

\begin{abstract}
Abstrak
Fokus penelitian ditetapkan pada Analisis Semiotika Iklan Coca-Cola versi Avatar mengenai pesan tersembunyi tentang keprihatihan sosial akan dampak perkembangan teknologi yang telah merubah masyarakat menjadi anti-sosial. Untuk mendukung penelitian ini penulis menggunakan teori dari Charles Sander Pierce yang mengklasifikasi jenis tanda berdasarkan objek kedalam tiga jenis, yaitu icon, index dan symbol. Dengan teori Pierce tersebut makna tanda-tanda yang terkandung didalam iklan Coca-Cola Versi Avatar akan di analisis.

Jenis penelitian yang digunakan adalah penelitian deskriptif kualitatif dengan pendekatan semiologi komunikasi. Data penelitian ini merupakan data kualitatif sehingga data bersifat kategori substansif yang kemudian diinterpretasikan dengan rujukan referensi-referensi ilmiah.

Coca-Cola Company juga ingin menyampaikan informasi bahwa di dalam era globalisasi/jaman milenial ini, banyak konsep-konsep sosial, seperti integrasi, kesatuan, persatuan, nasionalisme dan solidaritas, tampak semakin kehilangan realitas sosialnya dikarenakan dari penggunaan perangkat teknologi yang berlebihan. Berbagai realitas sosial yang berkembang dalam skala global, khusunya sebagai akibat dari kemajuan teknologi informasi, justru menggiring ke akhir sosial.
\end{abstract}

Kata Kunci : Iklan, Coca-Cola, Avatar, hiperrealitas

\begin{abstract}
The focus of the study is the Semiotic Analysis of the Coca-Cola Ad Avatar version of a hidden message about social concern about the impact of technological developments that have transformed society into anti-social. To support this research the author uses the theory of Charles Sander Pierce which classifies the type of sign based on objects into three types, namely icon, index and symbol. With Pierce's theory the significance of the signs contained in the Coca-Cola Avatar Version ads will be analyzed.

The type of research used is descriptive qualitative research with semiology communication approach. The data of this research is qualitative data so that the data is substansif category which then interpreted with reference of scientific references.

Coca-Cola Company also wants to convey the information that in this era of globalization / millenial era, many social concepts, such as integration, unity, nationalism and solidarity, seem to be losing their social reality owing to the excessive use of technological devices. The various social realities that develop on a global scale, especially as a result of advances in information technology, leads to social end.
\end{abstract}

Key Word : Advertisement, Coca-Cola, Avatar, hyperreality 


\section{PENDAHULUAN}

Pada dasarnya iklan memiliki fungsi yang sama dengan komunikasi massa pada umumnya, yaitu fungsi informasi, fungsi pendidikan, fungsi hiburan, dan juga fungsi persuasi. Namun yang paling menonjol dari iklan adalah fungsi persuasinya.

Dalam sebuah iklan tentu terdapat pesan yang ingin disampaikan pembuat iklan kepada khalayaknya, baik pesan yang berkaitan tentang informasi produk ataupun pesan di luar informasi produk, misalnya pesan sosial. Pesanpesan dalam iklan tidak selalu jelas terlihat, maka dari itu dibutuhkan pemikiran kritis khalayak untuk dapat menangkap tanda-tanda dari pesan yang ingin disampaikan dalam iklan tersebut, tanda-tanda tersebut dapat dikaji dengan menggunakan semiotika.

Deskripsi Analisis Semiotika Iklan CocaCola Versi Avatar ad for Super Bowl XLIII, 2009, merupakan bentuk keprihatihan sosial akan dampak perkembangan teknologi yang telah merubah masyarakat menjadi anti-sosial. Perusahaan Coca-Cola mengemas pesannya dan disampaikan dalam bentuk iklan, yang bertujuan untuk meningkatkan citra perusahaan dimata masyarakat khususnya konsumen serta bentuk kewajiban perusahaan dalam bidang CSR.

Iklan ini dibintangi oleh seorang aktor yang beradegan sedang melakukan sebuah perjalanan menuju ke sebuah kedai minuman. Disepanjang jalan tersebut diperlihatkan berbagai aktivitas masyarakat perkotaan yang modern, dimana segala aktivitasnya selalu di dukung oleh gadget dan terhubung dengan internet diantaranya: Handphone, Laptop, ipad, PSP, $d l l$. Dalam penggambarannya, manusia-manusia yang terhubung dengan gadget tersebut seketika berubah wujud menjadi sosok Avatar.

Penyampaian iklan ini diiringi musik serta lagu yang santai dan romantis yang menjadi pendukung pesan iklan. Narasi disampaikan diakhir iklan yang bertutur "CocaCola Open Happines" yang disandingkan dengan visualisasi botol Coca-Cola, yang membuat akhir iklan menjadi cukup manis.

\section{KERANGKA KONSEPTUAL}

Tanda adalah perangkat yang kita pakai dalam upaya memaknai "makna" yang terkandung didalamnya. Sehingga dalam semiotika hendak mempelajari bagaimana manusia memaknai hal-hal, memaknai berarti bahwa objek-objek itu tidak hanya membawa informasi. Dalam hal mana objek-objek itu hendak berkomunikasi, tetapi juga mengkonstruksi sistem terstruktur dari tanda (Sobur, 2013:15).

Iklan sebagai bahan kajian semiotika, sebuah iklan selalu berisikan unsur-unsur tanda berupa objek yang diiklankan; konteks berupa lingkungan, orang atau makhluk hidup lainnya yang memberikan makna pada objek; serta teks (berupa tulisan) yang memperkuat makna, meskipun yang terakhir ini tidak selalu hadir dalam sebuah iklan (Piliang 2012:306).

Secara sederhana iklan didefinisikan sebagai pesan yang menawarkan suatu produk yang ditujukan kepada masyarakat lewat media (Kasali, 1995:9). Iklan menjalankan fungsi kembar, pertama ia memberi informasi pada konsumen perihal ciri, kualitas, dan keunggulan produk. Kedua, iklan melakukan persuasi agar produk tersebut di beli oleh konsumen (Tinarbuko, 2007:2) Dengan kata lain iklan bertujuan memberikan informasi kepada khayalak mengenai suatu produk.

Iklan adalah sebuah ajang permainan tanda yang selalu bermain dalam tiga elemen tanda, yang satu sama lainnya saling mendukung. Dalam tampilan iklan terdapat berbagai macam tanda yang dibuat oleh pengiklan dalam usaha untuk

menarik minat khalayak.

Penggunaan sistem tanda dalam iklan diyakini penulis memiliki makna yang tersembunyi membuat penulis bermaksud mempelajari lebih dalam mengenai sistem tanda dalam iklan. Dan untuk itu penulis memilih ilmu semiotika sebagai metode yang sesuai untuk mengetahui makna dalam tanda yang terkandung dalam iklan.

Ide penulis dalam memilih "Analisis Semiotika dan Pesan Sosial Pada Iklan CocaCola Versi Avatar" berawal dari seringnya penulis menemukan iklan Coca-Cola yang ditampilkan di televisi. Tampilan iklan yang bertemakan tentang realitas sosial yang 
berkembang di masyarakat saat itu, didukung dengan objek-objek seperti benda, orang dan adegan merupakan tanda-tanda yang menarik untuk diteliti.

Merek Coca-Cola yang membuat penulis tertarik. Melihat latar belakang perusahaan dan eksistensi Coca-Cola ini tentu saja tujuan dari iklan mereka bukan hanya sekedar menjual keunggulan produk semata melainkan ada maksud dan tujuan lain yang ingin di sampaikan lewat ide, citra, gaya hidup serta rasa yang ingin di sampaikan lewat penggunaan tanda dalam iklan.

Untuk mendukung penelitian ini penulis menggunakan teori dari Charles Sander Pierce yang dikutip dalam buku Semiotika komunikasi dari Alex Sobur (2013), yang dimana teori Pierce mengklasifikasi jenis tanda berdasarkan objek kedalam tiga jenis, yaitu icon, index dan symbol.

Suatu tanda menandakan sesuatu selain dirinya. Tanda pada dasarnya akan

mengisyaratkan suatu makna yang dapaa) dipahami oleh manusia yang menggunakannya. Bagaimana manusia mengasosiasikan objek atau ide dengan tanda. Hal ini selaras dengan pendapat Charles Sander Pierce (dalam Soburb) 2003:15) bahwa semiotika sebagai “... $a$ relationsip of many sign, an object, and a meaning ..." (suatu hubungan diantara tanda, objek dan makna).

Charles Sander Pierce membagi tanda) berdasarkan objeknya, yaitu:

a) Icon adalah tanda yang hubungan penanda dan petandanya bersifat bersamaan bentuk alamiah atau dengan kata lain, ikon adalah hubungan antara tanda dan objek acuan yang bersifat kemiripan.

b) Index adalah tanda yang menunjukan adanya hubungan alamiah antara tanda dan petanda yang bersifat kausal atau hubungan sebab akibat, atau tanda yang langsung mengacu pada kenyataan.

c) Symbol adalah tanda yang menunjukan hubungan alamiah antara penanda dengan petandanya. Hubungan diantaranya bersifat arbiter atau semena, hubungan berdasarkan konvensi (perjanjian) masyarakat (Alex Sobur; 2013:42).
Semiotika iklan sebagai sebuah teks adalah sistem tanda terorganisir menurut kode-kode yang merepresentikan nilai-nilai tertentu, sikap dan juga keyakinan tertentu. Di dalam sebuah iklan terdapat pesan-pesan yang memiliki dua tingkatan makna yang dinyatakan secara eksplisit dipermukaan dan makna yang dikemukakan secara implisit dibalik permukaan iklan. Dengan demikian, semiotika menjadi metode yang sesuai untuk mengetahui konstruksi makna yang terjadi dalam iklan dengan menekankan peran sistem tanda dengan konstruksi realitas, maka melalui semiotika ideologi-ideologi dibalik iklan bisa diungkapkan.

Dalam iklan Coca-Cola versi avatar ini terdapat beberapa bentuk interkasi yang perlu dianalisis guna menentukan jenis tanda yang hal yang memaknainya.

Bentuk-bentuk interaksi antar manusia menurut teori Thompson, 1995 terdapat tiga bentuk, diantaranya:

Face-to-face interaction. Dalam Face-to-face interaction atau interaksi tatap muka, orangorang berbagi waktu dan ruang karena mereka hadir bersama.

Mediated Interaction. Dalam Mediated Interaction atau interaksi yang dimediasi pengiriman pesan dan penerimaan pesan, dipisahkan dalam ruang dan waktu dan media yang menyampaikan bentuk pesan tersebut.

Mediated quasi-interaction. Mediated quasiinteraction berbeda dengan mediated Interaction. Sebuah percakapan telepon atau pertukaran e-mail antara dua orang atau lebih adalah bentuk mediated Interaction. Sedangkan media massa seperti televisi, radio dan surat kabar adalah contoh dari Mediated quasiinteraction. Sebuah pesan $e$-mail ke mailing list juga merupakan bentuk Mediated quasiinteraction.

\section{HASIL DAN PEMBAHASAN}

Produk desain yang akan dikaji oleh penulis merupakan iklan televisi dari Coca-Cola Company, berikut adalah keterangan iklan : Judul Iklan

Produksi : Coca-Cola Avatar

Oleh : Coca-Cola

Argentina 
- Lokasi

Buenos Aires, Argentina

- Soundtrack Lagu

: Stranger In The Crowd

- Penyanyi

- Durasi

- Sumber

- Upload

: Gnarls Barkley

: 61 detik

: Coca-Cola

Superbowl

: 30 Januari 2009

Berdasarkan pengamatan penulis terhadap iklan Coca-Cola versi Avatar, Dalam tampilan iklan terdapat enam jenis tanda berdasarkan objeknya, yaitu:

1) Suasana Perkotaan

2) Wujud Manusia

3) Wujud virtual : Avatar

4) Emoticon, Balon kata, grafik dan colour

5) Senyuman, tatapan mata, dan dialog

6) Ikon Produk

7) Sosok Wanita

Berdasarkan hasil identifikasi maka jenis tanda dapat diklasifikasikan sebagai berikut:

\section{1). Suasana Perkotaan}

Tanda ini termasuk kedalam jenis symbol. Pada latar belakang iklan ini digambarkan sebuah jalan raya dengan laliu lintas yang cukup padat akan aktivitas pejalan kaki dan juga kendaraan. Digambarkan pula gedung-gedung bertingkat yang tinggi menjulang yang menaungi deretan pertokoan dan perkantoran, juga terdapat sebuah taman kota yang cukup ramai, yang dijadikan sebagi tempat bersantai, berinteraksi dan tempat hiburan masyarakat sekitar. Aktivitas manusia pun nampak terlihat hampir diseluruh bagian dari kota tersebut. Manusiamanusia yang ditampilkan menggunakan fashion dengan gaya yang modern dan hampir semua manusia digambarkan menggunakan perangkat teknologi.

Ciri dari kondisi diatas merupakan penggambaran atau symbol dari sebuah suasana perkotaan modern yang berada pada era globalisasi atau jaman milenial, dimana perangkat teknologi tidak bisa dilepaskan dari segala aktivitasnya.

\section{2). Wujud Manusia}

Tanda ini termasuk kedalam jenis tanda icon. Pada iklan ini ditampilkan aktivitas manusia perkotaan yang selalu terhubung dengan perangkat teknologi, sehingga kehilangan realitasnya dan menciptakan realitas semu, kemudian mereka digambarkan berubah dari wujud manusia menjadi wujud virtual, sedangkan manusia/hewan yang tidak menggunakan perangkat teknologi apapun dan tetap berada di dalam realitas digambarkan dalam wujud manusia seutuhnya.

Penggambaran ini merupakan tanda bahwa wujud manusia yang ditampilkan menjadi icon dari realitas, dimana kehadiran jiwa dan raganya tidak terusik karena tidak dipengaruhi oleh perangkat teknologi apapun.

\section{3). Wujud Virtual : Avatar}

Avatar pada iklan ini termasuk kedalam jenis tanda symbol. Dalam istilah umum, avatar adalah setiap representasi maya dari makhluk dalam lingkungan online, dan dapat termasuk manusia atau hewan dalam bentuk lain dalam media interaktif online. Setiap orang bebas untuk menciptakan avatar sendiri dengan tujuan sebagai simbol untuk komunikasi dengan pengguna lain. Avatar merupakan tampilan grafis berupa mahluk hidup, objek, atau simbol, yang menjadi lambang mewakili jati diri seseorang, biasanya di layanan chating atau forum. Pemakaian avatar biasanya difungsikan untuk menampilkan citra diri atau mood seseorang kepada publik di internet, tanpa harus menampilkan wajah/foto asli sang pengguna

Di dalam iklan ini terdapat: 2 plain avatar, 5 sims, 9 short people, 3 sports people, 5 animals, 2 super soldiers, 1 spy, 7 medieval fantasy people, 3 animal-people, 1 transformer, 2 mutants, 1 robot, 2 zombies, 2 digitalized people, 6 aliens, dan 1 superhero.

Mereka yang berubah menjadi sosok avatar memilih karakter yang hampir sesuai dengan citra dirinya, namun dibuat agar tampak lebih sempurna dari realitas dirinya. Misalnya, dalam kehidupan nyata fisik seseorang pendek dan gendut, namun tampilan avatarnya ternyata tinggi dan langsing.

Wujud virtual avatar ini merupakan sebuah symbol dari realitas semu, dimana manusia 
bertinteraksi dengan media melalui layar yang memiliki kedataran dan kedangkalan namun mampu menciptakan realitas semu (hiperrealitas). Manusia yang sedang berada di dalam realitas semu secara fisik hadir dalam realitas nyata, namun tidak hadir dengan kehadiran jiwanya.

\section{4) Emoticon, Balon kata, dan Grafik}

Tanda ini termasuk kedalam jenis tanda icon. Pada iklan Coca-Cola versi Avatar ini manusia-manusia yang melakukan interaksi dengan di mediasi oleh layar (layar $H P$, komputer, laptop, PSP, televisi, dll) menciptakan kedataran dan kedangkalan yang mampu membuat orang 'terjebak dan jatuh cinta' di dalam realitas semu, yang pada akhirnya dapat mengalihkan perhatian seseorang sehingga tidak peduli dengan keadaan realitas nyatanya. Mereka melakukan interaksi seperti bercakapan melalui handphone, bertukar pesan melalui email/aplikasi chat, bermain game online, transaksi online, dll. Aktivitis yang sedang mereka lakukan dapat diketahui dari keterangan icon-icon seperti (Emoticon, balon kata dan grafik) yang ditampilkan dengan cukup jelas menyertai gambaran avatarnya.

Dengan demikian keterangan emoticon, balon kata dan grafik, dapat dipahami sebagai tanda bahwa manusia/avatar tersebut sedang berinteraksi dengan media (mediateinteraction).

Mediated Interaction pada iklan coca cola versi Avatar ini menggambarkan sebuah tanda dari bentuk interaksi manusia di era globalisasi/jaman milenial, dimana banyak konsep-konsep sosial, seperti integrasi, kesatuan, persatuan, nasionalisme dan solidaritas, tampak semakin kehilangan realitas sosialnya.

Contoh cuplikan-cuplikan yang menunjukkan Mediated Interaction pada iklan coca cola versi Avatar terdapat pada tabel 3.1.

\section{5) Senyuman, tatapan mata, dan dialog}

Pada iklan ini terdapat pada adegan diakhir iklan Coca-Cola Avatar ini dimana terdapat sosok pria dan sosok wanita yang tanpa tidak disadari meraih sebuah botol Coco-Cola yang sama, sehingga keduanya terkejut dan saling menatap dan saling melempar senyuman dan akhirnya saling berdialog. Ciri tersebut merupakan ciri dari face-to-face interaction dimana terdapat terdapat dialogic, mutual presence, a high of contextual information dan terdapat adanya timbal balik atau reciprocal.
Cuplikan 1, Suasana menggambarkan sebuah pertokoan yang dikelilingi oleh jalan bertangga. Terdapat seorang ibu yang sedang berusaha memindahkan kereta dorong bayinya dari tangga bagian bawah menuju tangga bagian atas, ibu tersebut nampak kesulitan dan mengharapkan bantuan dari seorang pria yang ada di dekatnya. Pria tersebut ditampilkan dengan avatar Superhero.

Namun Superhero tersebut hanya duduk dengan mata tertuju pada laptop dan dilengkapi dengan icon yang ada di atas kepalanya menunjukkan bahwa dia sedang melakukan mediate-interaction.

Nilai-nilai sosial yang dimilki Superhero yaitu baik hati, suka menolong dan kuat, tidak nampak pada adegan diatas. Superhero tersebut tidak peduli dan tidak sadar akan masalah yang ada disekitarnya. Dia sedang berada di dalam realitas semunya dan kehilangan realitas sosialnya.

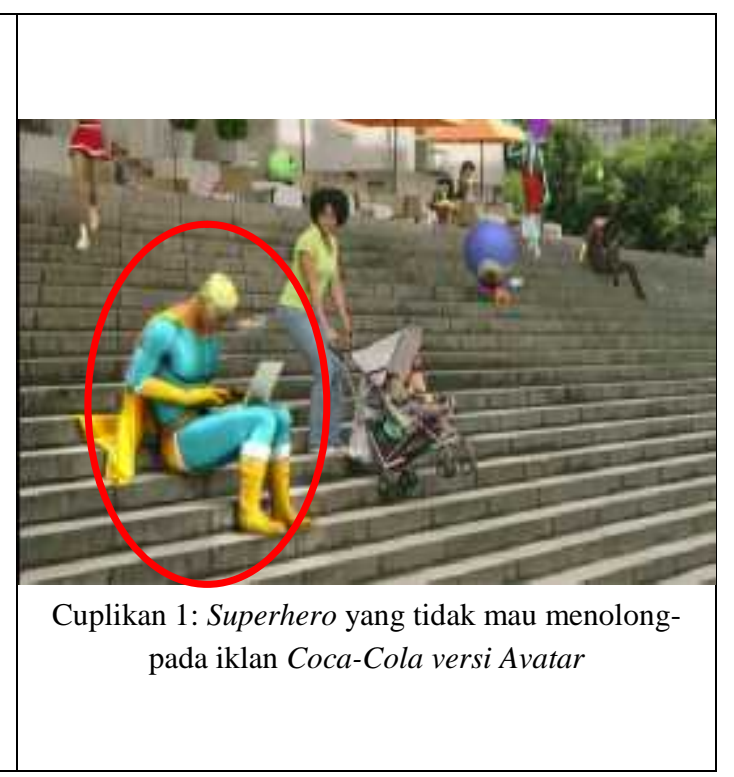




Cuplikan 2, Suasana menggambarkan sebuah taman
yang dilengkapi area bermain untuk anak-anak.
Terdapat seorang ibu dan seorang anak laki-laki
yang sedang bermain ayunan.
Yang menjadi perhatian pada adegan ini adalah
ekspresi sang ibu yang telihat lebih menikmati
hubungan yang didapatkan melalui mediate-
interaction dengan handphonenya, ketimbang
dengan anaknya. Terlihat dari keterangan iconnya
(balon kata), ibu tersebut sedang mengobrol
(Chatting) menggunakan aplikasi chat.
Secara harfiah, hubungan antara ibu dan anak
tidaklah dapat di pisahkan, baik secara fisik maupun
secara psikologi, namun dari gambaran diatas
tidaklah demikian. Penggunaan perangkat teknologi
yang tidak bijak dan waktu penggunaannya yang
tidak tepat, mampu merusak hubungan dan nilai
tersebut.
$\begin{aligned} & \text { Cuplikan 3, Suasana menggambarkan sebuah taman. } \\ & \text { Tampak seekor anjing yang terlihat ingin sekali } \\ & \text { bermain bola bersama namun tidak di tanggapi oleh } \\ & \text { pemiliknya. Pemilik anjing tersebut digambarkan } \\ & \text { dengan tampilan avatar yang berkostum pembalap } \\ & \text { yang nampak sedang asik bermain game dengan PSP } \\ & \text { nya, dilengkapi dengan keterangan icon (grafik level } \\ & \text { kecepatan/speed). } \\ & \text { Dia berinteraksi dengan game playernya, namun dia } \\ & \text { tidak hadir dalam lingkungan sekitarnya. Kewajiban } \\ & \text { dan tanggung jawab sebagai pemilik hewan } \\ & \text { peliharaan pun akhirnya tidak dapat dilaksanakan } \\ & \text { dengan baik. }\end{aligned}$

Tabel 3.1 contoh adegan-adegan yang menunjukkan Mediated Interaction pada iklan coca cola versi Avatar

\section{6) Ikon Produk : Coca-Cola}

Tanda ini termasuk kedalam jenis tanda icon. Dalam iklan Coca-Cola versi avatar ini icon produk dimunculkan pada saat adegan sosok pria dan sosok wanita yang tanpa tidak disadari meraih sebuah botol Coco-Cola yang sama, pada adegan ini botol Coca-Cola sebagai medium yang meyebabkan perubahan interaksi face- toface terjadi dan dapat mengembalikan gambaran realitas dari realitas semu kembali ke realitas nyata. Reaksi dan ekspresi yang di tunjukkan oleh aktor dan aktris memperlihatkan reaksi yang baik, positif, ceria, manis, terjadi timbal balik (saling menatap, dan tersenyum), maka secara tidak langsung CocaCola juga menyampaikan pesan bahwa "CocaCola dapat membuka jalan serta mampu mengembalikan realitas semu menjadi realitas nyata, dan hanya di dalam kehidupan nyata kesenangan, kebahagian dapat dirasakan".

\section{7) Sosok Wanita}

Tanda ini termasuk kedalam jenis tanda icon. Pada iklan ini sosok wanita pada awalnya disimulasikan dengan wujud avatar monster Oger (salah satu karakter dalam game online warcraft) yang merupakan musuh dari manusia. Namun kemudian ketika face-to-face interaction telah terjadi (ketika menyentuh botol Coca-Cola) monster Oger tersebut berubah wujud menjadi sosok wanita berusia sekitar 17-25 tahun, memiliki paras yang cantik, manis, menarik dan tampak ramah 
(bertolak belakang dengan penggambaran monster Oger).

Adegan dimana monster Oger berubah menjadi sosok wanita cantik ini adalah klimaks dari iklan Coca-Cola versi Avatar ini dimana perubahan bentuk interaksi telah terjadi, dari interaksi yang di mediasi oleh media (Mediated Interaction) menjadi interaksi tatap muka (Face-to-face interaction) yang mengharuskan hubungan timbal-balik hadir didalamnya. Ketika semuanya hadir (jiwa-raga, pria-wanita) realitas tercipta dengan sempurna dan indah. Sosok wanita dan senyumnya merupakan icon dari keindahan, kesenangan dan kebahagian.

Selain tanda berdasarkan objeknya, iklan ini juga dilengkapi dengan mode-mode pendukung diantaranya :

\section{1) Mode Music}

Mode music pada iklan ini adalah soundtrack lagu yang berjudul Stranger In The Crowd. Lirik lagunya menceritakan mengenai seorang pria yang sedang mengamati hiruk pikuk kota dari jendela kamarnya. Lagu ini menurut penulis sesuai dengan gambaran dari tampilan iklan di atas. Berikut adalah lirik dari lagu tersebut.
I'd been standing on the corner Since a quarter after seven

I was down to my last cigarette And the clock in the window

Had it quarter to eleven

I was watching all the people

Passing by me, going places

Just the loneliest guy in the town

Looking for a friendly smile

But all that I could see were faces

And then, just like the taste of milk and honey

I found the stranger I'd been looking for The way my cup of love was overflowing

I knew the stranger in the crowd

And I would be strangers no more

\section{2) Mode Writing}

Mode writing yang berupa teks "CocaCola Open Happines" terdapat pada bagian akhir iklan yang menandakan bahwa CocaCola dapat membuka jalan serta mampu mengembalikan realitas semu menjadi realitas nyata, dan hanya di dalam kehidupan nyata kesenangan, kebahagian dapat dirasakan".

\begin{tabular}{|l|l|}
\hline Tanda berdasarkan objeknya & Cuplikan adegan iklan Coca-Cola versi Avatar \\
\hline $\begin{array}{l}\text { Suasana Perkotaan } \\
\text { Ciri dari kondisi ini merupakan } \\
\text { sengambaran atau symbol dari } \\
\text { yang berada pada era globalisasi } \\
\text { atau jaman milenial, dimana } \\
\text { perangkat teknologi tidak bisa } \\
\text { dilepaskan dari segala } \\
\text { aktivitasnya. }\end{array}$ \\
$\begin{array}{l}\text { 2) } \\
\text { Wujud Manusia manusia yang } \\
\text { ditampilkan menjadi icon dari } \\
\text { realitas, dimana kehadiran jiwa } \\
\text { dan raganya tidak terusik } \\
\text { karena tidak dipengaruhi oleh } \\
\text { perangkat teknologi apapun. }\end{array}$
\end{tabular}




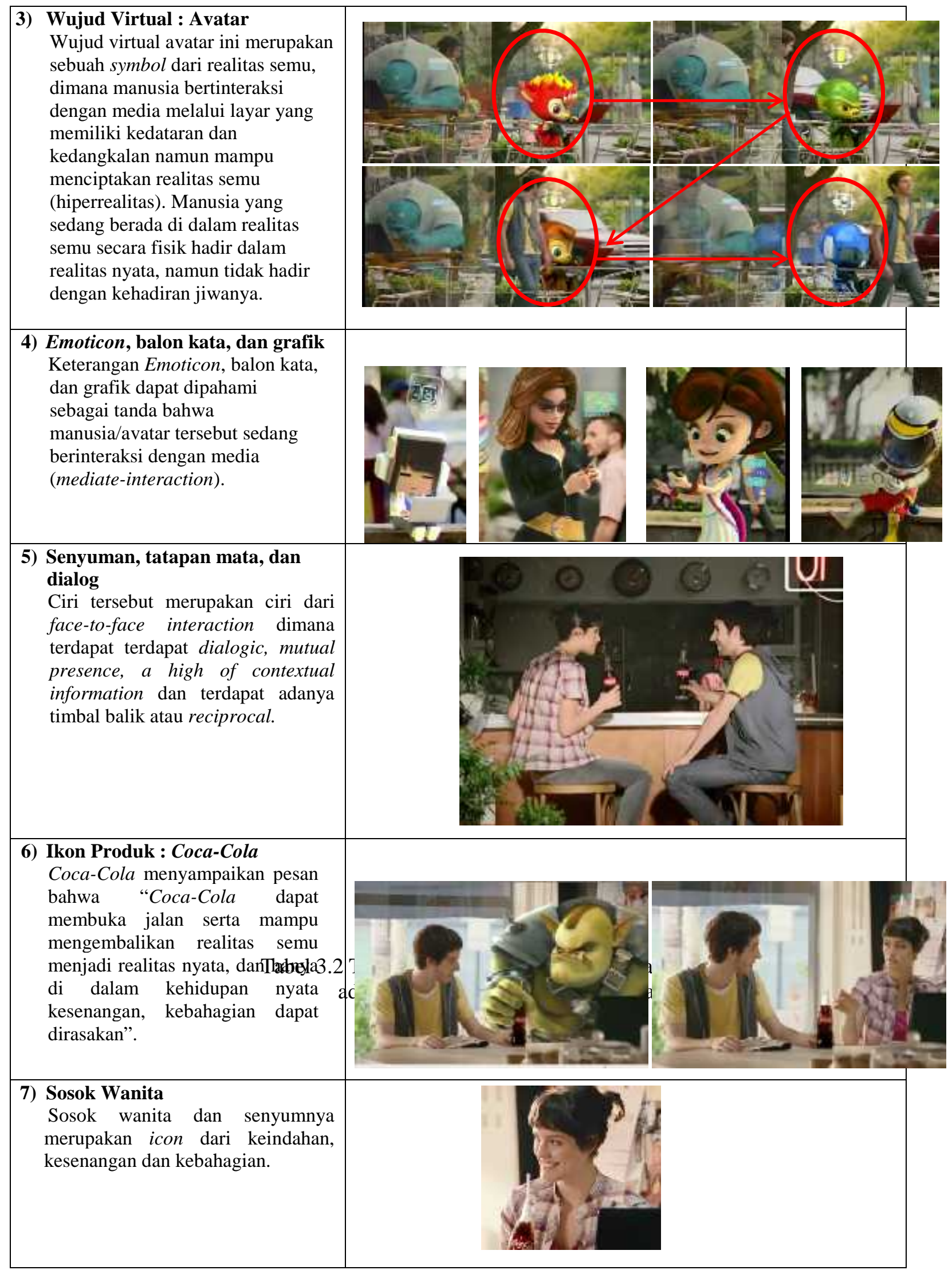




\section{KESIMPULAN}

Berdasarkan pengamatan dan hasil identifikasi di atas, dapat disimpulkan bahwa pesan yang ingin di sampaikan oleh Coca-Cola Company adalah mengenai fenomena perubahan bentuk interaksi yang terjadi akibat dari perkembangan teknologi, dimana manusia manusia banyak yang berinteraksi dengan media (Mediated Interaction dan mediated quasi-interaction) sehingga interaksi tatap muka (Face-to-face interaction menjadi tergantikan. Mediated Interaction dan mediated quasi-interaction menciptakan realitas semu dan di tampilkan dengan perubahan wujud manusia menjadi wujud virtual avatar.

Coca-Cola Company juga ingin menyampaikan informasi bahwa di dalam era globalisasi/jaman milenial ini, banyak konsepkonsep sosial, seperti integrasi, kesatuan, persatuan, nasionalisme dan solidaritas, tampak semakin kehilangan realitas sosialnya dikarenakan dari penggunaan perangkat teknologi yang berlebihan. Berbagai realitas sosial yang berkembang dalam skala global, khusunya sebagai akibat dari kemajuan teknologi informasi, justru menggiring ke akhir sosial.

Namun kondisi tersebut memang memang tengah terjadi pada kehidupan saat ini. Interaksi melalui media mampu membantu manusia dalam hal-hal tertentu, namun dapat juga menghasilkan misinterpretasi bagi penerima pesan, jika pesan yang disampaikan tidak sesuai dengan apa diterima. Selain itu Interaksi melalui media tersebut membentuk komunikasi non verbal yang didalamnya tidak terdapat suara, ekspresi wajah dan bahasa tubuh (body language) dan tidak bisa menghadirkan kesenangan dan kebahagiaan yang nyata.

\section{DAFTAR PUSTAKA}

Kasali, Rhenald. 1995. Manajemen Periklanan, Konsep dan Aplikasinya Di Indonesia. Jakarta: Pustaka Utama Grafiti.

Mulyana, Deddy. 2012. Ilmu Komunikasi Suatu Pengantar. Bandung: PT. Remaja Rosdakarya Offset.

Nurudin. 2009. Pengantar Komunikasi Massa. Jakarta: PT. Raja Grafindo Persada.
Piliang, Yasraf Amir. 2012. Terkurung di Antara Realitas-realitas Semu. Dunia Yang Dilipat.. Bandung: Matahari.

Sobur, Alex. 2013. Semiotika Komunikasi. Bandung: PT. Remaja Rosdakarya Offset.

Tinarbuko, Sumbo. 2007. Semiotika Iklan Sosial. Yogjakarta: Jalan

Whittaker, Steve. 2001. The effects of different affordances on communication behaviours and processes. Theories and Methods in Mediated Communication, 4-7. New Jersey: AT\&T Labs-Reasearch.

CocaColaSuperbowl. 2009. Coca-Cola Avatar. https://www.youtube. com/watch? $v=K w k e 0$ Lnardc. Diakses tanggal 14 Januari 2018 
e-ISSN: 2597-5188

Vol.1, No.1, April 2018 